\title{
Minimally invasive surgical interventions in the treatment of primary persistent hyperinsulinemic hypoglycemia of infancy
}

Fahimeh Soheilipour', Fatemeh Jesmi', Mohammad Ahmadi', Abdolreza Pazouki', Peyman Alibeigi', Mohammadreza Abdolhosseini'

\section{SUMMARY}

Hyperinsulinemia, diagnosed by laboratory tests, should be diagnosed and treated as soon as possible to prevent fatal complications such as neurological damage. Patients who are resistant to medical therapy should be treated surgically. Minimally invasive surgery, a newly developed approach, is a good choice among surgical procedures to avoid unnecessary extensive pancreatectomy. Here, a 12-year-old boy is presented with diagnosis of hyperinsulinemic hypoglycemia who had recurrent attacks of hypoglycemia and seizures from infancy. Because of his unresponsiveness to medical therapy and his family's preference, he underwent laparoscopic pancreatectomy to reduce morbidity and hospital stay. Two years postsurgical follow-up revealed a normo-glycemic state. Arch Endocrinol Metab. 2015;59(5):466-9
${ }^{1}$ Minimally Invasive Surgery Research Center, Iran University of Medical Sciences, Tehran, Iran

Correspondence to:

Abdolreza Pazouki

Minimally Invasive Surgery

Research Center

Iran University of Medical Sciences,

Tehran, Iran

apazouki@yahoo.com

Received on July/28/2014 Accepted on Apr/20/2015

DOI: 10.1590/2359-3997000000094

\section{INTRODUCTION}

$\mathrm{P}$ rimary persistent hyperinsulinemic hypoglycemia of infancy (PHHI), a rare inborn metabolic disease occurring due to excessive secretion of insulin, is diagnosed by glucose $<60 \mathrm{mg} / \mathrm{dL}$ in addition to elevated plasma insulin $(>2.0 \mathrm{pU} / \mathrm{mL})$. Early diagnosis is important due to probable neurologic sequel, but it is the treatment that seems to be a matter of concern in medicine ( 1 ).

PHHI is categorized into focal and diffuse via different pathogeneses introduced $(2,3)$. The treatment of choice for adenomatous hyperplasia of pancreatic cells, micro or macro adenoma, is surgical removal (4). On the contrary, diffuse hyperplasia, arisen by islet cell dysregulation of insulin production, can only be cured by near-total (95\%) pancreatectomy as the initial procedure of choice when medical therapy has failed (5). According to probable postoperational problems, especially diabetes mellitus due to $\beta$-cell dysfunction (6), a biopsy is mandatory to distinguish the two forms of PHHI (7).

Minimally invasive procedures are used increasingly each year to minimize the invasion and side effects in various surgical procedures. Other advantages of mini- mally invasive procedures include avoidance of large wounds, less postoperative pain, lower rate of morbidity, earlier hospital discharge, and cosmetic benefits (8).

Here it is aimed to emphasize the importance of early diagnosis and the role of minimally invasive surgeries in the diagnosis and treatment of hyperinsulinemic status.

\section{CASE REPORT}

The patient is a 12-year-old obese boy who was admitted with recurrent hypoglycemic attacks followed by seizures and speech problems. During his first visit, his hallux was broken due to a recent trauma in a generalized tonic clonic seizure, and he had a bottle of sugary water in his hand, drinking every few minutes. His birth history was complicated by macrosomia and a birth weight of 5,200 g. His birth height was $60 \mathrm{~cm}$. His mother was not diabetic, and he had no family history of documented hypoglycemia or any other inborn error of metabolism. In physical examination, his height was $117.5 \mathrm{~cm}(2.5 \mathrm{z}$ score $)$, his weight was $30.2 \mathrm{~kg}(1.1 \mathrm{z}$ score), and his body mass index was calculated at 27.27 $\mathrm{kg} / \mathrm{m}^{2}$. The examination revealed bilateral lipomastia 
and pubertal tanner stage 1 both at gonadal and pubic stages. He was in the $5^{\text {th }}$ grade with a good educational status, having never failed during his education. He had recurrent attacks of hypoglycemia from neonatal period that were diagnosed as PHHI and treated with $10 \mathrm{mg} / \mathrm{kg}$ diazoxide daily and frequent feeding.

Hyperinsulinemia was confirmed in this patient by a fasting serum insulin of $9 \mathrm{pU} / \mathrm{mL}$. He had low free fatty acids (both $<1.0 \mathrm{mmol} / \mathrm{L}$ ), an inappropriate glycemic response to intravenous glucagon $(>30 \mathrm{mg} / \mathrm{dL}$ rise in serum glucose level), and negative ketones in urine dipstick. Serum lactate, ammoniac, C-peptide, chromatography of serum amino acid and urine sugars, morning cortisol, prolactin, and thyroid function tests were all normal (Table 1). Abdominal computered tomographic scan with intravenous and oral contrast did not reveal pancreatic adenoma. Due to his resistance to medical therapy and his family's decision, he was scheduled for surgical intervention. A laparoscopic biopsy was obtained, which revealed diffuse hyperplasia of the pancreas; sections showed pancreatic tissue with normal acinar structure, intermixed with islets of Langerhans which are different in size and shape. The cells of the latter showed mild atypia characterized by vesicular nuclei with mild nuclear pleomorphism and enlargement, small nuclei and pale eosinophilic cytoplasm. No ductuloinsular complexes was identified in multiple sections examined (Figure 1).
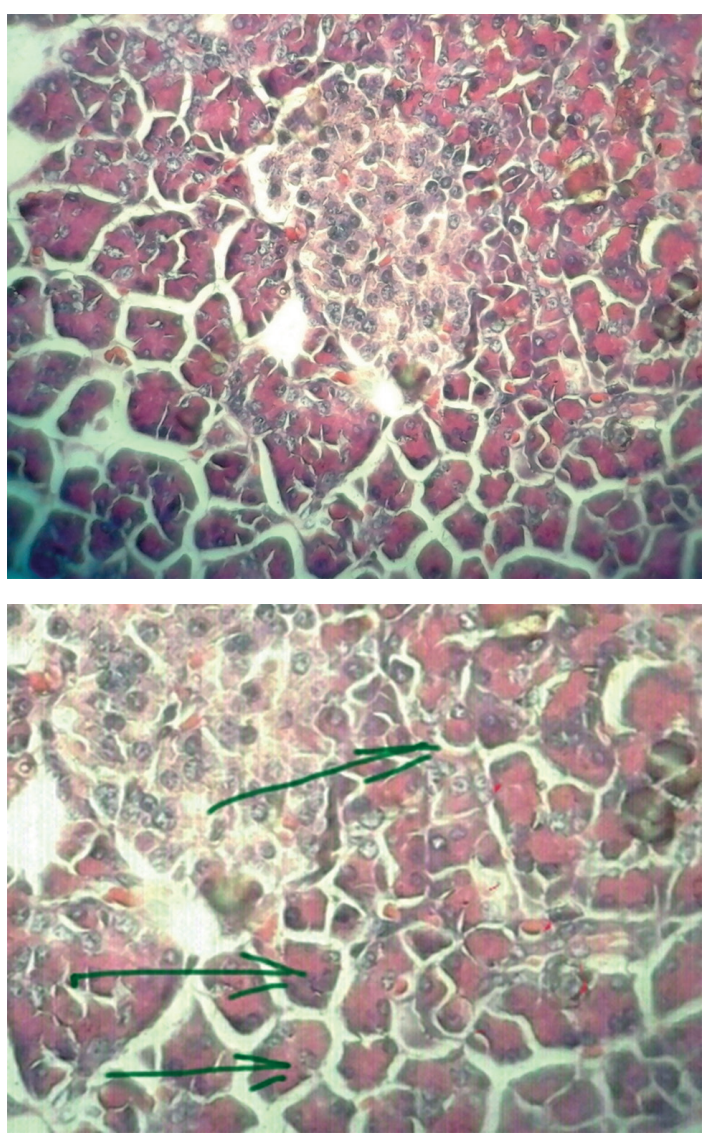

Figure 1. Pathologic finding: pleomorphism with large nuclei and vesicular nuclei (marked). The cells of the latter showed mild atypia characterized by vesicular nuclei with mild nuclear pleomorphism and enlargement, small nuclei and pale eosinophilic cytoplasm. No ductuloinsular complexes was identified in multiple sections examined.

Table 1. The results of serum tests of the patient

\begin{tabular}{|c|c|c|c|c|c|}
\hline Serum tests & Patient's result & Reference value & Unit & Method & Instrument \\
\hline Fasting serum insulin & 9 & $2.6-24.5$ & $\mu \mathrm{lU} / \mathrm{mL}$ & Electrochemiluminescency & Elecsys 2010 Roche HITACHI \\
\hline Lactate & 4 & $2.5-20$ & $\mathrm{mg} / \mathrm{dL}$ & Colorimetric & BT 3000 \\
\hline Ammoniac & 26 & $\begin{array}{c}\text { Male: 25-94 Female: } \\
19-82\end{array}$ & $\mu \mathrm{g} / \mathrm{dL}$ & Colorimetric & BT 3000 \\
\hline C-peptide & 2.5 & $0.8-3.1$ & $\mathrm{ng} / \mathrm{mL}$ & Electrochemiluminescency & Elecsys 2010 Roche HITACHI \\
\hline $\begin{array}{l}\text { Chromatography of serum } \\
\text { amino acids and }\end{array}$ & Normal pattern & - & - & HPLC & Kenovera \\
\hline $\begin{array}{l}\text { Chromatography of urine } \\
\text { sugars }\end{array}$ & Normal pattern & - & - & TLC & Kenovera \\
\hline Morning cortisol & 32 & $5-25$ & $\mu \mathrm{g} / \mathrm{dL}$ & Electrochemiluminescency & Elecsys 2010 Roche HITACHI \\
\hline Prolactin & $\mathrm{NL}$ & $\begin{array}{c}\text { - Males: } 2 \text { - } 18 \\
\text { - Non-pregnant } \\
\text { women: } \\
2 \text { - } 29 \\
\text { - Pregnant women: } \\
10 \text { - } 209\end{array}$ & $\mathrm{ng} / \mathrm{mL}$ & Electrochemiluminescency & Elecsys 2010 Roche HITACHI \\
\hline $\mathrm{T} 4$ & 8 & $4.5-12.5$ & $\mu \mathrm{g} / \mathrm{dL}$ & Electrochemiluminescency & Elecsys 2010 Roche HITACHI \\
\hline T3 & 132 & Adults: 0.8 - 2.0 & $\mathrm{ng} / \mathrm{ml}$ & Electrochemiluminescency & Elecsys 2010 Roche HITACHI \\
\hline TSH & 2.5 & $0.5-4.70$ & $\mathrm{mlU} / \mathrm{L}$ & Electrochemiluminescency & Elecsys 2010 Roche HITACHI \\
\hline
\end{tabular}


Then a laparoscopic pancreatectomy of about $85 \%$ of the pancreas was performed (Figure 2). The patient was positioned supine, legs apart, with the surgeon standing between the patient's legs. The camera holder was on the patient's right side and the surgeon's assistant on the patient's left side. The first trocar was placed into the abdomen above the umbilicus, with open technique, and a $12-\mathrm{mm}$-trocar about $7 \mathrm{~cm}$ at the umbilical level on the left side of the abdomen. One 5-mm-trocar was inserted $5 \mathrm{~cm}$ on the anterior axillary line, one 5 -mm-trocar on the mid-clavicular line on the patient's right side, and the last 5-mm-trocar on the epigastrium.

A 5-mm-ligasure was used for dissection and the gastrocolic meso was first cut to enter the lesser sac. There was no evidence of mass on pancreatic surface. The pancreas was examined with intraoperative laparoscopic ultrasonography, which detected no adenoma. A biopsy was taken from body of pancreas and sent for frozen section, which confirmed PHHI. So, pancreatectomy was scheduled for this case. The midcolic vein was found and followed to its entrance beneath the pancreas neck and was then dissected beneath it along the superior mesenteric vein until the superior border of the pancreas. Then the neck was transected with a purple EndoGIA tri-stapler, and the body and tail of the pancreas was dissected from its attachments, preserving the splenic artery and vein. After distal pancreatectomy, a corrugated silicone drain was positioned in place.

The patient's postoperational general condition was good with no complications. The drain was removed five days after the operation. Postsurgical follow-up for two years showed a normo-glycemic state and no occurrence of diabetes mellitus.

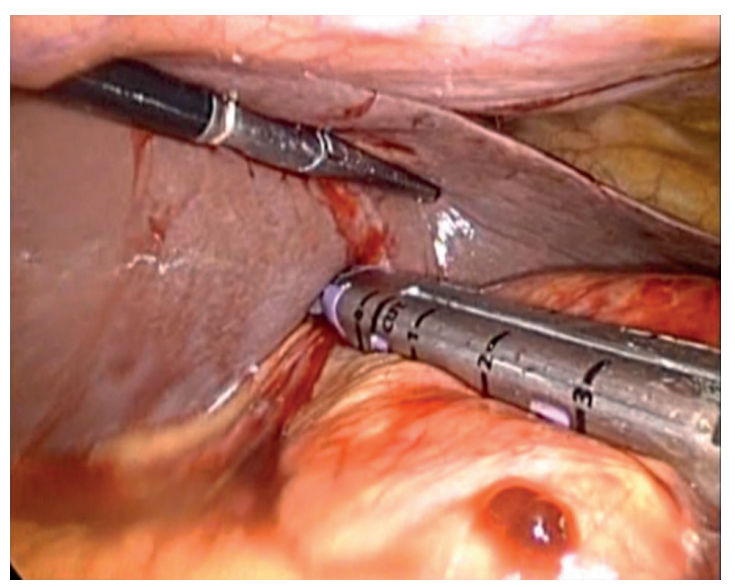

Figure 2. The laparoscopic procedure: There was no evidence of mass on pancreatic surface.

\section{DISCUSSION}

Minimally invasive surgical techniques have previously been used in other hyperinsulinemic statuses, like insulinomas $(9,10)$. The medical group chose this technique as a result of the patient's poor drug compliance, which helped him avoid receiving a more invasive intervention than needed.

Although medical therapy in combination with frequent enteral feeding (11) is the first choice for treatment of hyperinsulinemia (12), the response varies widely on clinical subtypes of PHHI, categorized by hyperinsulinemia severity and types of genetic mutations causing hypersecretion of insulin $(12,13)$. The risk of hypoglycemic attacks will also rise by increasing the feeding intervals; and as long as older children eat three separate meals, they will be more predisposed to hypoglycemia between the meals; therefore drug therapy will be less effective in controlling blood sugar with increasing age. On the other hand, older children have less drug compliance, as they may feel ashamed to use drugs in school or in front of their friends, or might resist doctor's visits, which may altogether cause poorer quality of life for them (14).

Additionally, the response rate of diazoxide, as the cornerstone of drug therapy, is partial and depends on many factors (15). Prevalent complications, such as hypertrichosis, have also been proposed for diazoxide. Serious complications including pulmonary hypertension, heart failure and neutropenia (16), hepatomegaly, severe fluid retention, diffuse edema, congestive heart failure, and respiratory failure requiring mechanical ventilation (17) have also been reported. Another problem that exists in our country is the fact that diazoxide is not always available, due to sanctions.

Studies have assessed the efficacy of various surgical procedures on this rare disease, but few have investigated the minimally invasive approaches. Al-Shanafey and cols. performed laparoscopic pancreatectomy for infancy with a median of $90 \%$ extent of resection and revealed many advantages for this procedure including accurate visualization, shorter hospitalization, less postoperative pain, early feeding, and good cosmetic results (18). One year later, he compared ten laparoscopic pancreatectomies with open procedure and concluded that the open group needs a higher extent of resection and the laparoscopic group is able to have earlier feeding (19).

Berends and cols. introduced conventional intraoperative ultrasonography combined with contact ultrasonography for better localization of insulinoma (20). 
Because of the small size of the adenomas, radiologic imaging studies often fail to localize them. Iihara and Obara proposed better laparoscopic resection of insulinoma when located in the body or tail of the pancreas (21). Intra-operative frozen section biopsy, requiring less extended pancreatectomy, has been proven to play an essential role in identifying cases of adenoma (22).

The accurate extent of pancreatectomy serves as a pitfall for surgeons, as it may induce diabetes or recurrent hypoglycemia (23). Ninety-five percent pancreatectomy is more challenging with more risk of bleeding due to the high risk of dissection and ligation of fragile venous branches between superior mesenteric, portal vein and head of pancreas Our surgical team took an intraoperative specimen for frozen section, and performed $85 \%$ pancreatectomy to decrease the possibility of diabetes mellitus, as $95 \%$ has a higher risk of diabetes mellitus. The patient is also still in a normoglycemic state, two years after the surgery.

Few studies have followed up with patients after the procedure. On the other hand, the laparoscopic approach we performed has rarely been used for this diagnosis. Its major advantages include better visualization and localization of the mass. An interesting point of this case can also be minimal neurological damage contrary to delayed patient treatment.

In conclusion, minimally invasive pancreatectomy is a good choice for the diagnosis and treatment of hyperinsulinemic hypoglycemia, with better visualization and a less invasive procedure to avoid unnecessary extensive morbidities.

Acknowledgment: we thank the Minimally Invasive Surgery Research Center surgery team.

Disclosure: no potential conflict of interest relevant to this article was reported.

\section{REFERENCES}

1. Stanley CA. Hyperinsulinism in infants and children. Pediatr Clin North Am. 1997;44(2):363-74.

2. Stanley CA, LieuYK, Hsu BY, Burlina AB, Greenberg CR, Hopwood $\mathrm{NJ}$, et al. Hyperinsulinism and hyperammonemia in infants with regulatory mutations of the glutamate dehydrogenase gene. $\mathrm{N}$ Engl J Med. 1998;338(19):1352-7.

3. Glaser B, Kesavan P, Heyman M, Davis E, Cuesta A, Buchs A, et al. Familial hyperinsulinism caused by an activating glucokinase mutation. N Engl J Med. 1998;338(4):226-30.

4. Rothmund M, Angelini L, Brunt LM, Farndon JR, Geelhoed G, Grama $D$, et al. Surgery for benign insulinoma: an international review. World J Surg. 1990;14(3):393-8; discussion 398-9.
5. Lovvorn HN 3rd, Nance ML, Ferry RJ Jr, Stolte L, Baker L, O'Neill $\mathrm{JA} J \mathrm{r}$, et al. Congenital hyperinsulinism and the surgeon: lessons learned over 35 years. J Pediatr Surg. 1999;34(5):786-92; discussion 792-3.

6. Leibowitz G1, Glaser B, Higazi AA, Salameh M, Cerasi E, Landau $H$. Hyperinsulinemic hypoglycemia of infancy (nesidioblastosis) in clinical remission: high incidence of diabetes mellitus and persistent beta-cell dysfunction at long-term follow-up. J Clin Endocrinol Metab. 1995;80(2):386-92.

7. Fékété $\mathrm{CN}$, de Lonlay $\mathrm{P}$, Jaubert F, Rahier J, Brunelle F, Saudubray JM. The surgical management of congenital hyperinsulinemic hypoglycemia in infancy. J Pediatr Surg. 2004;39(3):267-9.

8. Jaffray B. Minimally invasive surgery. Arch Dis Child. 2005;90(5):53742.

9. Fernández-Cruz L, Martínez I, Cesar-Borges G, Astudillo E, Orduña D, Halperin I, et al. Laparoscopic surgery in patients with sporadic and multiple insulinomas associated with multiple endocrine neoplasia type 1. J Gastrointest Surg. 2005;9(3):381-8.

10. Isla A, Arbuckle JD, Kekis PB, Lim A, Jackson JE, Todd JF, et al. Laparoscopic management of insulinomas. Br J Surg. 2009;96(2):185-90.

11. Aynsley-Green A, Hussain K, Hall J, Saudubray JM, NihoulFékété $C$, De Lonlay-Debeney $P$, et al. Practical management of hyperinsulinism in infancy. Arch Dis Child Fetal Neonatal Ed. 2000;82(2):F98-107.

12. Mazor-Aronovitch $\mathrm{K}$, Landau H, Gillis D. Surgical versus non-surgical treatment of congenital hyperinsulinism. Pediatr Endocrinol Rev. 2009;6(3):424-30.

13. Touati G, Poggi-Travert F, Ogier de Baulny H, Rahier J, Brunelle F, Nihoul-Fekete $\mathrm{C}$, et al. Long-term treatment of persistent hyperinsulinaemic hypoglycaemia of infancy with diazoxide: a retrospective review of 77 cases and analysis of efficacy-predicting criteria. Eur J Pediatr. 1998;157(8):628-33.

14. Landau $H$, Perlman M, Meyer S, Isacsohn M, Krausz M, Mayan $H$, et al. Persistent neonatal hypoglycemia due to hyperinsulinism: medical aspects. Pediatrics. 1982;70(3):440-6.

15. Macmullen CM, Zhou Q, Snider KE, Tewson PH, Becker SA, Aziz $A R$, et al. Diazoxide-unresponsive congenital hyperinsulinism in children with dominant mutations of the $\beta$-cell sulfonylurea receptor SUR1. Diabetes. 2011;60(6):1797-804.

16. Yildizdas D, Erdem S, Küçükosmanoglu O, Yilmaz M, Yüksel B. Pulmonary hypertension, heart failure and neutropenia due to diazoxide therapy. Paediatr Anaesth. 2004;14(7):607-9.

17. Silvani $P$, Camporesi A, Mandelli A, Wolfler A, Salvo I. A case of severe diazoxide toxicity. Pediatr Anaesthesia. 2004;14:607-9.

18. Al-Shanafey S, Habib Z, AINassar S. Laparoscopic pancreatectomy for persistent hyperinsulinemic hypoglycemia of infancy. $J$ Pediatr Surg. 2009;44(1):134-8.

19. Al-Shanafey S. Laparoscopic vs open pancreatectomy for persistent hyperinsulinemic hypoglycemia of infancy. J Pediatr Surg. 2009;44(5):957-61.

20. Berends FJ, Cuesta MA, Kazemier G, van Eijck CH, de Herder WW, van Muiswinkel JM, et al. Laparoscopic detection and resection of insulinomas. Surgery. 2000;128(3):386-91.

21. lihara M, Obara T. Section 6. Digestive organs: Minimally invasive endocrine surgery: laparoscopic resection of insulinomas. Biomed Pharmacother. 2002;56(Suppl 1):227-30.

22. Suchi M, Thornton PS, Adzick NS, MacMullen C, Ganguly A, Stanley $\mathrm{CA}$, et al. Congenital hyperinsulinism: intraoperative biopsy interpretation can direct the extent of pancreatectomy. Am J Surg Pathol. 2004;28(10):1326-35.

23. Cresto J, Abdenur J, Bergada I, Martino R. Long term follow up of persistent hyperinsulinaemic hypoglycaemia of infancy. Arch Dis Child. 1998;79(5):440-4. 